Published in final edited form as:

Semin Perinatol. 2019 April ; 43(3): 123-131. doi:10.1053/j.semperi.2019.01.001.

\title{
The United States opioid epidemic
}

\author{
Jennifer Lyden a,b, ${ }^{*}$ and Ingrid A. Binswanger ${ }^{b, c, d}$ \\ aDenver Health and Hospital Authority, Denver, CO, United States \\ bDepartment of Medicine, University of Colorado School of Medicine, Denver, CO, United States \\ 'Institute for Health Research, Kaiser Permanente Colorado, Aurora, CO, United States \\ ${ }^{\mathrm{d} C}$ Colorado Permanente Medical Group, Aurora, CO, United States
}

\begin{abstract}
The United States opioid epidemic is a nationwide public health crisis. Initially driven by increased consumption and availability of pharmaceutical opioids, an increasing number of opioid overdoses are now related to heroin and illicitly manufactured fentanyl and fentanyl analogs. Addressing this epidemic requires addressing the stigma associated with opioid use disorders and its treatment, improving access to efficacious treatment options, specifically methadone and buprenorphine, and reducing opioid overdose fatalities with distribution of the opioid antagonist and overdose reversal agent naloxone.
\end{abstract}

\section{Keywords}

Opioids; Overdose; Epidemiology

\section{Introduction}

The United States is experiencing a nationwide public health crisis that continues to escalate. ${ }^{1-4}$ Between 2005 and 2014, the national rate of opioid-related hospitalizations increased $64 \%$ to 225 hospitalizations per 100,000 population. ${ }^{1}$ Death rates have also increased and in 2016, over 42,000 Americans died from an opioid overdose (OD); a 27\% increase in death rate from $2015 .{ }^{4}$ While regional and sociodemographic variations exist, the epidemic is widespread. ${ }^{1-4}$

\section{History}

The medicinal properties of opiates such as morphine and heroin, drugs naturally derived from the opium poppy, were first recognized in the 1800s and marketed to physicians and patients as a safe and effective way to alleviate the suffering. ${ }^{5,6}$ With limited federal and industry oversight, opioids were used freely by doctors and lay persons to treat everyday

*Corresponding author at: Denver Health, 601 Broadway, MC 4000, Denver, CO 80204, United States. Jennifer.lyden@ dhha.org (J. Lyden).

Authors' contribution

$\mathrm{JL}$ wrote the manuscript and $\mathrm{IAB}$ critically revised the manuscript. 
ailments such as cough, diarrhea, anxiety and minor pains. With increased use, some also noted the associated risks of opioids. In 1889, James Adams noted that opium, "while surpassing other remedies in its beneficent effects" was "alike remarkable in its power of harm." Mirroring sentiment from today, Adams also noted the disadvantages of opium being threefold; "(1) In an overdose it is an active poison. (2) In ordinary doses, its benefits are largely offset by various functional derangements. (3) Its use involves the danger of the opium-habit." 7

With pressure from Adams and like-minded colleagues, a change in culture occurred. ${ }^{5}$ By the early 1900s, appropriate and advanced medical care was thought to include a restrained approach to opioid use. By 1915, the Harrison Anti-Narcotic Act also took effect, which regulated opioid prescribing and dispensing practices. ${ }^{8}$ These initiatives are thought to have led to a decrease in opioid consumption, helping to curtail the nation's first opioid crisis.

As foreshadowed at the turn of the twentieth century, the modern-day epidemic has also been closely linked to increases in opioid consumption and liberal prescribing practices by clinicians. ${ }^{9-11}$ Starting largely in the 1980s, attitudes toward pain management and opioid safety began to shift. Previously, these medications had been reserved for severe cancer pain, end-of-life care and limited episodes of acute pain. However, pain specialists and patient advocacy groups began to raise awareness of the inadequate treatment of non-cancer pain and underutilization of pharmaceutical opioids. For example, in 1985 an editorial published in Advances in Alcohol and Substance Abuse reported that physicians "markedly undertreat" pain and expressed concern for "opiophobia" - an "irrational and undocumented" fear that patients will become addicted to opioids when opioids are used appropriately. ${ }^{12}$ This sentiment was echoed by the President of the American Pain Society (APS) in a published editorial that advocated for improved pain control and encouraged use of opioids to achieve this, writing "therapeutic use of opiate analgesics rarely results in addiction". ${ }^{13}$ What followed was a movement by the APS to focus on pain and pain control; referring to it as the "fifth vital sign" necessitating repeated monitoring and intervention. 11,14 The Joint Commission (formerly The Joint Commission on the Accreditation of Healthcare Organizations) also intervened and in 2001 set new pain management standards, which tied healthcare quality and patient satisfaction to pain control. ${ }^{11,14,15}$

Reports of pharmaceutical opioid safety often cited a one paragraph letter published in the New England Journal of Medicine in $1980 .{ }^{16}$ In this correspondence, the authors briefly reported findings from a retrospective, observational study that assessed the side effects of opioids in hospitalized patients. This limited information was frequently used to highlight safety and promote increased prescribing by clinicians for chronic, non-cancer pain. For example, promotional video conferences and training sessions produced and funded by large pharmaceutical companies, and targeted toward physicians, inaccurately reported the risk of addiction as "less than one percent". 17

Compounding this, in 1995 the new extended-release (ER) oxycodone was approved by the Food and Drug Administration (FDA) for use and marketed to physicians as a safe and effective opioid pain reliever. The extended release formulation, it was argued, provided a slow, sustained release of medication which posed a lower risk for a "high" when compared 
to immediate release opioids. ${ }^{18,19}$ Marketing campaigns seized on this theory, promoting ER oxycodone as an abuse deterrent formulation with very low risk for iatrogenic addiction. ${ }^{17}$ At the time however, there were little data to support this claim. ${ }^{17,20}$ Studies have since shown that ER oxycodone has a similar efficacy and safety profile as immediate release opioid pain relievers ${ }^{21-23}$ and in 2001, the FDA required that this claim be removed from drug labeling. ${ }^{24}$

Paralleling the increased attention to pain management and widespread marketing campaigns, opioid prescribing increased, peaking at 225 million prescriptions dispensed and a rate of 81.2 prescriptions per 100 persons in $2010 .{ }^{25}$ In conjunction, diversion and nonmedical use (i.e., the use of pharmaceutical opioids without a prescription or in a way that was not intended by the prescribing clinician) also increased, ${ }^{26-28}$ and between 1999 and 2009 death rates involving pharmaceutical opioids increased nearly fourfold. ${ }^{29}$

After a period of stabilization, opioid prescribing rates began declining in 2012 and have declined each year from 2012 to $2017 .{ }^{30}$ Nonetheless, due in large part to upsurges in fatal overdoses involving heroin and more recently, illicitly manufactured fentanyl (IMF) and highly potent fentanyl analogues, opioid overdose deaths continue to rise. ${ }^{4,31}$

\section{Distinctions between tolerance, dependence, and opioid use disorder}

An opioid is any substance that binds to opioid receptors in the central nervous system. Opioids can be (1) endogenous, i. e. endorphins, (2) naturally occurring opium alkaloids derived directly from the opium poppy, or (3) semi-synthetic or synthetic compounds. Naturally occurring opioids such as morphine and codeine may also be referred to as opiates. Heroin, which is made from morphine, and oxycodone, are examples of semisynthetic opioids. Fully synthetic opioids, such as methadone and fentanyl, have chemical structures different than opium alkaloids but bind to the same opioid receptors in the central nervous system, triggering similar analgesic and euphoric effects.

Although opioid tolerance, dependence and opioid use disorder (OUD) represent distinct phenomena with markedly different clinical implications, their relationship is often misunderstood. ${ }^{32}$ Opioid tolerance and dependence are anticipated, physiologic adaptations in the body that occur with repeated meaningful doses of opioid substances, either pharmaceutical or illegal. Tolerance, defined as a diminished response to a substance that occurs with frequent use, often requires that patients use increasing opioid doses to achieve an equivalent analgesic response. ${ }^{33,34}$ Dependence means that a person may experience signs or symptoms of withdrawal when their dose is decreased or stopped abruptly. 33,34 Theses responses are not unique to opioids and may occur with other medications or substances such as antihypertensive medications, corticosteroids or even caffeine.

Unlike tolerance and dependence, OUD is not an anticipated or adaptive response to repeated opioid exposure. ${ }^{33}$ The hallmark of a use disorder is a problematic pattern of behavior characterized by intense "cravings" that contribute to "compulsive drug seeking and use, despite harmful consequences." 35 The diagnostic criteria for OUD are outlined in the Diagnostic and Statistical Manuel of Mental Disorders (DSM), Fifth Edition ${ }^{36}$ (Table 1). 
This diagnosis replaces the separate previous diagnoses from DSM-IV of "substance abuse" and "substance dependence". 37

Similar to other substance use disorders, OUD is a complex disease not fully understood by clinicians and researchers. While there are numerous ways to conceive and understand addiction in light of individual and social factors, addiction is commonly understood to be disease of the brain where recurrent exposure to a substance alters its structure and function, ultimately contributing to the compulsive drug-seeking behavior cardinal to OUD. ${ }^{38,39}$ However, not all people who are exposed to opioids will develop an OUD. ${ }^{32}$ Genetic, environmental and social factors interact to make some patients more vulnerable than others. Further, some medical complications of OUD are the result of limited access to effective preventive strategies, such as sterile syringes, which result from legal policies rather than purely biological phenomena. ${ }^{40,41}$

OUD is often compared to chronic diseases such diabetes and heart disease, where daily medication and lifestyle modification are needed to improve symptoms (e.g. cravings) and reduce adverse health outcomes (e.g. HIV, hepatitis C, overdose). ${ }^{42,43}$ Similar to other chronic diseases, treatment adherence is often imperfect and recurrence of use can be common.

Neonatal abstinence syndrome (NAS) is a postnatal withdrawal syndrome that is closely linked to OUD. Strictly speaking, NAS refers to withdrawal syndromes in neonates caused by any substance, however, with the increasing incidence of fetal opioid exposure in-utero, NAS commonly refers to neonatal opioid withdrawal. ${ }^{44-46}$ For infants with consistent prenatal opioid exposure of any kind, it is an expected and manageable outcome. Prenatal opioid exposure includes chronic pharmaceutical opioid therapy under a doctor's supervision for severe pain, methadone or buprenorphine pharmacotherapy for OUD or illicit use of substances such as heroin.

Misunderstandings about NAS are common. For instance, infants who develop NAS are not born "addicted" to opioids. ${ }^{47}$ The cardinal feature of addiction is a problematic pattern of behavior, which is not possible in neonates. There is also a common misperception that higher maternal opioid doses are tied to the onset and severity of NAS. However, several studies have examined the relationship between methadone dose and the incidence and severity of NAS with mixed results. ${ }^{48-50}$ When restricted to prospective studies using an objective scoring system, a meta-analysis by Cleary et al. found no statistical difference in the incidence and severity of NAS by methadone dose. ${ }^{51}$ This suggests that other factors should be considered when determining maternal methadone during pregnancy, such as adequate control of withdrawal symptoms and relapse risk.

Both methadone and buprenorphine can be used to treat women with OUD during pregnancy. A multicenter, double blind randomized control trial, the Maternal Opioid Treatment; Human Experimental Research (MOTHER) study, examined neonatal outcomes in pregnancies with maternal exposure to methadone or buprenorphine. ${ }^{52}$ Investigators demonstrated that, while there was no difference in the number of infants requiring treatment for NAS between the groups, buprenorphine pharmacotherapy was associated with 
lower morphine requirements, shorter duration of NAS treatment, and shorter infant hospital stays. This study suggested less severe NAS with buprenorphine treatment when compared to methadone. Similarly, a 2013 Cochrane review, which included the MOTHER study, also suggested less severe NAS with buprenorphine. However, the authors also reported increased treatment retention in those receiving methadone compared to buprenorphine.

Citing variation across outcomes, as well as the small body of evidence, the authors concluded there was insufficient evidence to support one treatment over the other. ${ }^{53}$

\section{Epidemiology}

According to the National Survey on Drug Use and Health, a national, population-based household survey, in 2016, 11.8 million Americans 12 or older reported misuse of opioids (i.e., non-medical use of pharmaceutical opioids or use of heroin) in the last year. Of these, 92\% misused pharmaceutical opioids only, 5.4\% misused pharmaceutical opioids and heroin and $2.6 \%$ used heroin only. ${ }^{54}$

In 2016, over 42,000 Americans died from an opioid overdose, representing a 27\% increase in death rates from opioid overdoses from 2015 (13.3 per 100,000 population). ${ }^{4}$ Heroin, IMF and highly potent fentanyl analogs are now implicated in the majority of fatal opioid overdoses. The Centers for Disease Control and Prevention (CDC) estimate that over 80\% of the opioid overdose deaths in 2016 involved heroin or a synthetic opioid other than methadone (i.e., fentanyl). ${ }^{55}$ Between 1999 and 2016, the rate of deaths involving heroin increased seven-fold (from 0.7 per 100,000 in 1999 to 4.9 in 2016) and the rate of deaths involving synthetic opioids increased twenty-fold (from 0.3 per 100,000 in 1999 to 6.2 per 100,000 in 2016). This includes a $100 \%$ increase in synthetic opioid overdose death rates from 2015 to $2016 .^{55}$

Historically, men have been disproportionately affected by opioids with higher overall rates of OUD and overdose mortality than women, however the prevalence of OUD and its complications are rising in women. ${ }^{3}$ Between 2005 and 2014, opioid-related hospitalizations increased for both men and women. However, rate increases were more for women than for men ( $75 \%$ vs $55 \%$ ) and by 2014 , in most states, the rate of opioid-related inpatient stays for women exceeded that of men. ${ }^{1}$

Mirroring increases in the general population, opioid use and OUD in women who are pregnant have increased. ${ }^{56-59}$ Between 1999 and 2014, the rate of antepartum opioid use disorder quadrupled (from 1.5 to 6.5 per 1000 hospital births) ${ }^{60}$ and opioids are now the most common reason for seeking drug treatment during pregnancy. ${ }^{61}$ Concurrently, the incidence of NAS increased $400 \%$ from 2000 to $2012,{ }^{62,63}$ and national medical costs for NAS were estimated at \$316 million in 2012 alone. ${ }^{64}$

\section{Confronting the opioid epidemic}

\section{Reducing stigma}

The language used in discussing and treating patients with substance use disorders is important. Incorrect terminology may unknowingly contribute to misunderstandings about 
OUD, perpetuate stigma and bolster stereotypes; collectively reinforcing treatment barriers for patients. ${ }^{65,66}$

Studies have found that terms such as "addict" and "substance abuser" elicit strong negative feelings toward individuals suffering from OUD. ${ }^{67}$ This can imply that addiction occurs as a fault of the person, such as a personality flaw or moral failing, requiring punitive measures, 68 rather than as a result of a medical condition. ${ }^{38,39}$

"Person first" language has been suggested as a way to address stigma and stereotypes in OUD. ${ }^{65,69}$ In person first language, words describing individuals precede words describing their disease or disorder. ${ }^{70}$ For example, consider "patient with a history of opioid use disorder" versus "opioid abuser" or "addict". The former, helps to focus on the person and not their disorder, conveying that while they may suffer from OUD, it is not their only identity.

The language used to describe medications used to treat OUD can also be pejorative. ${ }^{71,72}$ Treatment with the opioid agonists methadone or buprenorphine is often referred to as "opioid substitution therapy" or "medication assisted treatment". Experts argue that this terminology supports the false notion that these medications are "replacing one addiction for another" and suggests that pharmacotherapy is merely an adjunct to other aspects of addiction care. ${ }^{71,73}$ Contrary to this, the scientific literature strongly supports the use of methadone and buprenorphine as a safe and effective way to reduce illicit drug use and improve societal engagement. ${ }^{74}$

\section{Improving prescribing practices}

Although prescribing rates have declined in recent years, the increased availability and use of opioid pain medications played an important role in the modern-day epidemic. In 2016, the amount of prescription opioid medications in the United States was roughly three times as high as in 1999, ${ }^{25,75}$ and in 2016, over 17,000 died from a pharmaceutical opioid overdose. ${ }^{4}$ Several studies have shown a temporal and spatial relationship between the availability of pharmaceutical opioids and overdose mortality. ${ }^{10,27,76,77}$ Even when prescribed by a physician and taken as instructed, use of pharmaceutical opioids can lead to adverse health outcomes including addiction and fatal overdoses. ${ }^{78}$ Evidence suggests that these risks are increased with long acting opioid formulations, long term opioid therapy, high morphine equivalent doses, concurrent benzodiazepine use, and past history of substance use disorders, tobacco use, and mental health diagnoses. ${ }^{79-83}$

In 2016 the CDC released guidelines with 12 specific recommendations (Table 2) to assist clinicians in prescribing pharmaceutical opioid medications to treat pain and recognize and treat patients with high-risk behaviors or OUD. ${ }^{84}$ The primary focus of these recommendations pertained to medical management of pain lasting $>3$ months and did not pertain to cancer or end-of-life care. Acute pain management was also briefly addressed.

Prescription drug monitoring programs (PDMP) have also been established in nearly every state to improve prescribing practices. Several states report PDMP effectiveness in process outcomes such as improving physician confidence, ${ }^{85,86}$ identifying patients with multiple 
prescribers, and reducing availability of controlled substances. ${ }^{87}$ Patrick et al also demonstrated that state PDMP implementation was associated with a decrease of 1.12 opioid-related overdose deaths per 100,000 population annually. States that monitored four or more drug schedules and updated their PDMP regularly had even great reductions in mortality rates. ${ }^{88}$ Current CDC guidelines suggest reviewing PDMP data prior to all opioid prescriptions and at minimum, prior to initiating long-term opioid therapy and periodically during its course. ${ }^{84}$

\section{Increasing utilization of medications for opioid use disorder}

There are three FDA-approved medications to treat patients with OUD-methadone, buprenorphine and naltrexone. Methadone and buprenorphine are long-acting opioid receptor agonists that provide consistent systemic drug levels and have been shown to reduce opioid cravings ${ }^{89}$ and prevent withdrawal syndromes. ${ }^{90}$ Naltrexone, an opioid receptor antagonist, is available as an oral medication requiring daily dosing or as an injectable medication requiring monthly dosing. When taken appropriately, naltrexone blocks the effects of opioids and can prevent relapse. However, adherence to daily dosing is challenging and a 2011 Cochrane Review suggested that oral naltrexone was no better than placebo or no pharmacotherapy in preventing relapse or improving treatment retention. ${ }^{91}$ Studies investigating the efficacy of extended-release naltrexone have been more promising; 92,93 however, concerns remain regarding the overdose risk in patients treated with naltrexone only. ${ }^{94,95}$

Studies have repeatedly shown that methadone and buprenorphine reduce illicit opioid use, increase retention in drug treatment, and reduce mortality. ${ }^{96-101}$ For example, a systematic review and meta-analysis of cohort studies published in the British Medical Journal in 2017 found that patients who received maintenance buprenorphine or methadone had substantially reduced all-cause and overdose mortality rates when compared to patients who did not receive opioid agonist medications. ${ }^{102}$ A Cochrane review by Mattick et al in 2009 and 2014 also showed that when compared to placebo, both buprenorphine and methadone were effective in retaining people in treatment. ${ }^{74,99}$

Despite a substantial evidence base, agonist pharmacotherapy for OUD remains underutilized. Barriers are multifold and include a lack of trained prescribers to initiate and maintain medications, misperceptions by patients and providers about how medications work and their intended outcomes and fear of stigma or criminalization by patients.

Unlike methadone, which can only be dispensed by licensed, specialty treatment programs with daily dosing, the Drug Addiction Treatment Act of 2000 (DATA 2000) allows buprenorphine to be prescribed by waivered physicians and advanced practice providers in an office-based setting to treat OUD. ${ }^{103}$ Studies suggest this has improved access to pharmacotherapy for many patients with OUD; however, access remains poor. For example, Jones et al estimated that in 2012, if all available methadone treatment slots were filled and all buprenorphine waivered physicians saw the maximum number of patients allowed, over 900,000 patients would still be in need of pharmacotherapy. ${ }^{104}$ This shortfall is particularly dire in rural areas of the country where over half $(56.3 \%)$ of all counties lack a single buprenorphine provider. ${ }^{105}$ Patrick et al also found that while most providers were accepting 
new patients in Appalachia, providers were less likely to accept women who were pregnant (91\% vs $75 \%)$.

In addition to problems with access, pregnant women with OUD may also face fears of criminalization when seeking pharmacotherapy to treat OUD. In 2014, Tennessee was the first state to pass a statute specifically allowing women to be prosecuted for assault if they engaged in illegal drug use during pregnancy. Currently, 23 states and the District of Columbia consider substance abuse during pregnancy to be child abuse and 24 states mandate healthcare workers to report substance abuse if suspected. ${ }^{106}$ This legal trend is concerning considering, the data suggest that women who are pregnant and receive methadone or buprenorphine are less likely to relapse on illicit opioids and more likely to engage in routine prenatal care, ${ }^{53,107-109}$ leading to better health outcomes for mother, fetus and infant.

\section{Reducing fatal overdoses}

Naloxone, an opioid receptor antagonist, is an antidote to opioid overdoses. ${ }^{110}$ Observational studies have repeatedly shown that take home naloxone is a safe and effective way to reduce OD mortality in patients with OUD ${ }^{111-114}$ and is not known to lead to an increase in substance use. ${ }^{115,116}$

The effectiveness of naloxone requires that overdose bystanders can (1) easily access the medication, (2) promptly recognize the signs and symptoms of OD and (3) effectively administer a life-saving dose. As such, most states have moved beyond traditional prescription models for distribution; allowing for third party prescriptions for anyone who may encounter an overdose and non-patient specific prescriptions where pharmacies and community health programs may distribute naloxone to any individual and provide education and training on OD recognition and medication administration. ${ }^{117}$ Guidelines suggest that clinicians offer naloxone to patients with OUD and consider offering it to patients on chronic opioid therapy when risk factors for opioid overdose are present such as concomitant benzodiazepine use, opioid doses over 50 morphine milligram equivalents per day, history of opioid overdose or other substance use disorder. ${ }^{84} \mathrm{~A}$ risk prediction model has been developed to help providers select patients prescribed chronic opioid therapy who could benefit from naloxone. ${ }^{83}$

\section{Conclusion}

Initially driven by increases in the availability of pharmaceutical opioids, fatal overdoses are now largely related to the emergence of illegally manufactured fentanyl and fentanyl analogues. Mortality statistics are grim; however, research has consistently shown improved outcomes with the use of pharmacotherapy to treat OUD, including for women who are pregnant. Clinicians can help reduce the stigma associated with OUD and barriers to treatment by using appropriate terminology that is non-judgmental and non-punitive. These efforts may help to address the opioid epidemic. 


\section{Acknowledgments}

Funding: Drs. Binswanger and Lyden were supported by grant 1R56DA044302. The content is solely the responsibility of the authors and does not necessarily represent the official views of the National Institute on Drug Abuse or the National Institutes of Health.

\section{REFERENCES}

1. Weiss AJ, Bailey MK, O'malley L, Barrett ML, Elixhauser A, Steiner CA. Patient Characteristics of Opioid-Related Inpatient Stays and Emergency Department Visits Nationally and by State, 2014. www.hcup-us.ahrq.gov/faststats/landing.jsp Accessed August 12, 2018.

2. Martins SS, Sampson L, Cerdá M, Galea S. Worldwide prevalence and trends in unintentional drug overdose: a systematic review of the literature. Am J Public Health. 2015;105(11):e29-e49. 10.2105/AJPH.2015.302843.

3. Jones CM, Logan J, Gladden RM, Bohm MK. Vital Signs: demographic and substance use trends among heroin users - United States, 2002-2013. MMWR Morb Mortal Wkly Rep. 2015;64(26): 719-725. http://www.ncbi.nlm.nih.gov/pubmed/26158353 Accessed March 12, 2018. [PubMed: 26158353]

4. Seth P, Scholl L, Rudd RA, Bacon S. Overdose deaths involving opioids, cocaine, and psychostimulants — United States, 2015-2016. MMWR Morb Mortal Wkly Rep. 2018;67(12):349358. 10.15585/mmwr.mm6712a1. [PubMed: 29596405]

5. Courtwright DT. Preventing and treating narcotic addiction - a century of federal drug control. N Engl J Med. 2015;373(22):2095-2097. 10.1056/NEJMp1508818. [PubMed: 26605925]

6. Trickey E Inside the story of America's 19th-century opiate addiction I history I smithsonian. 2018 https://www.smithso-nianmag.com/history/inside-story-americas-19th-century-opiateaddiction-180967673/ Accessed August 25, 2018.

7. ADAMS JFA. Substitutes for opium in chronic diseases. Bost Med Surg J. 1889;121(15):351-356. 10.1056/NEJM188910101211502.

8. Terry CE. The harrison anti-narcotic act.. Am J Public Health (N Y). 1915;5(6):518 http:// www.ncbi.nlm.nih.gov/pubmed/18009247 Accessed August 25, 2018. [PubMed: 18009247]

9. Centers for Disease Control and Prevention (CDC). Vital signs: overdoses of prescription opioid pain relievers and other drugs among women-United States, 1999-2010. MMWR Morb Mortal Wkly Rep. 2013;62(26):537-542. http://www.ncbi.nlm.nih.gov/pubmed/23820967 Accessed July 22, 2018. [PubMed: 23820967]

10. Hui Chen L, Hedegaard H, Warner M. Drug-Poisoning Deaths Involving Opioid Analgesics: United States, 1999-2011 Key Find-ings. 1999 http://www.cdc.gov/nchs/ Accessed July 22, 2018.

11. Meldrum ML. The ongoing opioid prescription epidemic: historical context. Am J Public Health. 2016;106(8):1365-1366. 10.2105/AJPH.2016.303297. [PubMed: 27400351]

12. Morgan JP. American opiophobia: customary underutilization of opioid analgesics. Adv Alcohol Subst Abuse. 1985;5(1-2):163-173. 10.1300/J251v05n01_11. [PubMed: 2870626]

13. Max MB. Improving outcomes of analgesic treatment: is education enough. Ann Intern Med. 1990;113(11):885-889. http://www.ncbi.nlm.nih.gov/pubmed/2240903 Accessed August 13, 2018. [PubMed: 2240903]

14. Tompkins DA, Hobelmann JG, Compton P. Providing chronic pain management in the \&quot; Fifth Vital Sign \& quot; Era: Historical and treatment perspectives on a modern-day medical dilemma. Drug Alcohol Depend. 2017;173(Suppl 1(Suppl 1)): S11-S21. 10.1016/j.drugalcdep. 2016.12.002. [PubMed: 28363315]

15. Baker DW. History of the joint commission's pain standards. JAMA. 2017;317(11):1117 10.1001/ jama.2017.0935. [PubMed: 28241189]

16. Porter J, Jick H. Addiction rare in patients treated with narcotics. N Engl J Med. 1980;302(2):123 http://www.ncbi.nlm.nih.gov/pubmed/7350425 Accessed August 25, 2018.

17. Van Zee A The promotion and marketing of oxycontin: commercial triumph, public health tragedy. Am J Public Health. 2009;99(2):221-227. 10.2105/AJPH.2007.131714. [PubMed: 18799767] 
18. In the United States District Court For The Western District of Virginia Abingdon Division United States of America). http://i.bnet.com/blogs/purdue-agreed-facts.pdf. Accessed September 5, 2018.

19. Purdue and the OxyContin Files I Kaiser Health News. https://khn.org/news/purdue-and-theoxycontin-files/. Accessed September 5, 2018.

20. Oxycodone and oxycontin. Med Lett Drugs Ther. 2001;43(1113):80-81. http:// www.ncbi.nlm.nih.gov/pubmed/11581580 Accessed September 4, 2018. [PubMed: 11581580]

21. Chou R, Clark E, Helfand M. Comparative efficacy and safety of long-acting oral opioids for chronic non-cancer pain: a systematic review. J Pain Symptom Manage. 2003;26(5):1026-1048. http://www.ncbi.nlm.nih.gov/pubmed/14585554 Accessed August 25, 2018. [PubMed: 14585554]

22. Rischitelli DG, Karbowicz SH. Safety and efficacy of controlled-release oxycodone: a systematic literature review. Pharmacotherapy. 2002;22(7):898-904. http://www.ncbi.nlm.nih.gov/pubmed/ 12126222 Accessed August 25, 2018. [PubMed: 12126222]

23. Hale ME, Fleischmann R, Salzman R, et al. Efficacy and safety of controlled-release versus immediate-release oxycodone: randomized, double-blind evaluation in patients with chronic back pain. Clin J Pain. 1999;15(3):179-183. http://www.ncbi.nlm.nih.gov/pubmed/10524470 Accessed September 4, 2018. [PubMed: 10524470]

24. Baker DW. History of the joint commission's pain standards. JAMA. 2017;317(11):1117 10.1001/ jama.2017.0935. [PubMed: 28241189]

25. Guy GP, Zhang K, Bohm MK, et al. Vital signs: changes in opioid prescribing in the United States, 2006-2015. MMWR Morb Mortal Wkly Rep. 2017;66(26):697-704. 10.15585/mmwr.mm6626a4. [PubMed: 28683056]

26. Hall AJ, Logan JE, Toblin RL, et al. Patterns of abuse among unintentional pharmaceutical overdose fatalities. JAMA. 2008;300(22):2613 10.1001/jama.2008.802. [PubMed: 19066381]

27. Cicero TJ, Surratt H, Inciardi JA, Munoz A. Relationship between therapeutic use and abuse of opioid analgesics in rural, suburban, and urban locations in the United States. Pharmacoepidemiol Drug Saf. 2007;16(8):827-840. 10.1002/pds.1452. [PubMed: 17636553]

28. Compton WM, Volkow ND. Abuse of prescription drugs and the risk of addiction. Drug Alcohol Depend. 2006;83:S4-S7. 10.1016/j.drugalcdep.2005.10.020. [PubMed: 16563663]

29. Calcaterra S, Glanz J, Binswanger IA. National trends in pharmaceutical opioid related overdose deaths compared to other substance related overdose deaths: 1999-2009. Drug Alcohol Depend. 2013;131(3):263-270. 10.1016/j.drugalcdep.2012.11.018. [PubMed: 23294765]

30. U.S. Prescribing Rate Maps I Drug Overdose I CDC Injury Center. https://www.cdc.gov/ drugoverdose/maps/rxrate-maps.html. Accessed June 18, 2018.

31. Hedegaard H, Warner M, Miniño AM. Drug Overdose Deaths in the United States, 1999-2016. 1999 https://www.cdc.gov/nchs/data/databriefs/db294.pdf. Accessed June 4, 2018.

32. Volkow ND, McLellan AT. Opioid abuse in chronic pain - misconceptions and mitigation strategies Longo DL, ed. N Engl J Med. 2016;374(13):1253-1263. 10.1056/NEJMra1507771. [PubMed: 27028915]

33. Kosten TR, George TP. The neurobiology of opioid dependence: implications for treatment. Sci Pract Perspect. 2002;1(1):13-20. http://www.ncbi.nlm.nih.gov/pubmed/18567959 Accessed August 20, 2018. [PubMed: 18567959]

34. Williams JT, Christie MJ, Manzoni O. Cellular and synaptic adaptations mediating opioid dependence. 2001 http://physrev.physiology.org . Accessed August 20, 2018.

35. The Science of Drug Abuse and Addiction: The Basics I National Institute on Drug Abuse (NIDA). https://www.druga-buse.gov/publications/media-guide/science-drug-abuse-addiction-basics. Accessed 20 August 2018.

36. American Psychiatric Association. Diagnostic and statistical manual of mental disorders: DSM-5. Am Psychiatr Assoc. 2013: 991 10.1176/appi.books.9780890425596.744053.

37. Hasin DS, O'Brien CP, Auriacombe M, et al. DSM-5 criteria for substance use disorders: recommendations and rationale. Am J Psychiatry. 2013;170(8):834-851. 10.1176/appi.ajp. 2013.12060782. [PubMed: 23903334]

38. Younger JW, Chu LF, D’ Arcy NT, Trott KE, Jastrzab LE, Mackey SC. Prescription opioid analgesics rapidly change the human brain. Pain. 2011;152(8):1803-1810. 10.1016/j.pain. 2011.03.028. [PubMed: 21531077] 
39. Upadhyay J, Maleki N, Potter J, et al. Alterations in brain structure and functional connectivity in prescription opioid-dependent patients. Brain. 2010;133(Pt 7):2098-2114. 10.1093/brain/awq138. [PubMed: 20558415]

40. Bixler D, Corby-Lee G, Proescholdbell S, et al. Access to Syringe services programs — Kentucky, North Carolina, and West Virginia, 2013-2017. MMWR Morb Mortal Wkly Rep. 2018;67(18): 529-532. 10.15585/mmwr.mm6718a5. [PubMed: 29746453]

41. Perlman DC, Jordan AE. The Syndemic of Opioid Misuse, Overdose, HCV, and HIV: structurallevel causes and interventions. Curr HIV/AIDS Rep. 2018;15(2):96-112. 10.1007/ s11904-018-0390-3. [PubMed: 29460225]

42. Kim TW, Saitz R, Cheng DM, Winter MR, Witas J, Samet JH. Initiation and engagement in chronic disease management care for substance dependence. Drug Alcohol Depend. 2011;115(1-2):80-86. 10.1016/j.drugalcdep.2010.10.013. [PubMed: 21168981]

43. Saitz R, Larson MJ, Labelle C, Richardson J, Samet JH. The case for chronic disease management for addiction. J Addict Med. 2008;2(2):55-65. 10.1097/ADM.0-b013e318166af74. [PubMed: 19809579]

44. Raffaeli G, Cavallaro G, Allegaert K, et al. Neonatal abstinence syndrome: update on diagnostic and therapeutic strategies. Pharmacother J Hum Pharmacol Drug Ther. 2017;37(7):814-823. 10.1002/phar.1954.

45. Bagley S, Wachman EM, Holland E, Brogly SB. Review of the assessment and management of neonatal abstinence syndrome. Addict Sci Clin Pract. 2014;9(1):19 10.1186/1940-0640-9-19. [PubMed: 25199822]

46. Kocherlakota P. Neonatal abstinence syndrome. Pediatrics. 2014;134(2):e547-e561. 10.1542/peds. 2013-3524. [PubMed: 25070299]

47. Shapiro BJ, Azari S, Jones HE. Stigmatizing language about neonatal abstinence syndrome. JAMA. 2018;320(7):723 10.1001/jama.2018.7820.

48. Dryden C, Young D, Hepburn M, Mactier H. Maternal methadone use in pregnancy: factors associated with the development of neonatal abstinence syndrome and implications for healthcare resources. BJOG. 2009;116(5):665-671. 10.1111/j.1471-0528.2008.02073.x. [PubMed: 19220239]

49. Bakstad B, Sarfi M, Welle-Strand GK, Ravndal E. Opioid maintenance treatment during pregnancy: occurrence and severity of neonatal abstinence syndrome. A national prospective study. Eur Addict Res. 2009;15(3):128-134. 10.1159/000210042. [PubMed: 19332991]

50. Lim S, Prasad MR, Samuels P, Gardner DK, Cordero L. High-dose methadone in pregnant women and its effect on duration of neonatal abstinence syndrome. Am J Obstet Gynecol. 2009;200(1). 10.1016/j.ajog.2008.08.041: 70.e1-5. [PubMed: 18976737]

51. Cleary BJ, Donnelly J, Strawbridge J, et al. Methadone dose and neonatal abstinence syndromesystematic review and meta-analysis. Addiction. 2010;105(12):2071-2084. 10.1111/j. 1360-0443.2010.03120.x. [PubMed: 20840198]

52. Jones HE, Kaltenbach K, Heil SH, et al. Neonatal abstinence syndrome after methadone or buprenorphine exposure. N Engl J Med. 2010;363(24):2320-2331. 10.1056/NEJMoa1005359. [PubMed: 21142534]

53. Minozzi S, Amato L, Bellisario C, Ferri M, Davoli M. Maintenance agonist treatments for opiatedependent pregnant women. Cochrane Database Syst Rev. 122013 10.1002/14651858.CD006318.pub3.

54. Results from the 2016 National Survey on Drug Use and Health. https://www.samhsa.gov/sites/ default/files/sites/default/files/2016_ffr_1_slideshow_v5.pdf. Accessed July 22, 2018.

55. O’Donnell JK, Gladden RM, Seth P. Trends in deaths involving heroin and synthetic opioids excluding methadone, and law enforcement drug product reports, by census region - United States, 2006-2015. MMWR Morb Mortal Wkly Rep. 2017;66(34):897-903. 10.15585/ mmwr.mm6634a2. [PubMed: 28859052]

56. Epstein RA, Bobo WV, Martin PR, et al. Increasing pregnancy-related use of prescribed opioid analgesics. Ann Epidemiol. 2013;23(8):498-503. 10.1016/j.annepidem.2013.05.017. [PubMed: 23889859] 
57. Desai RJ, Hernandez-Diaz S, Bateman BT, Huybrechts KF. Increase in prescription opioid use during pregnancy among medicaid-enrolled women. Obstet Gynecol. 2014;123(5):997-1002. 10.1097/AOG.0000000000000208. [PubMed: 24785852]

58. Bateman BT, Hernandez-Diaz S, Rathmell JP, et al. Patterns of opioid utilization in pregnancy in a large cohort of commercial insurance beneficiaries in the United States. Anesthesiology. 2014;120(5):1216-1224. 10.1097/ALN.0000000000000172. [PubMed: 24525628]

59. Stover MW, Davis JM. Opioids in pregnancy and neonatal abstinence syndrome. Semin Perinatol. 2015;39(7):561-565. 10.1053/j.semperi.2015.08.013. [PubMed: 26452318]

60. Haight SC, Ko JY, Tong VT, Bohm MK, Callaghan WM. Opioid use disorder documented at delivery hospitalization — United States, 1999-2014. MMWR Morb Mortal Wkly Rep. 2018;67(31):845-849. 10.15585/mmwr.mm6731a1. [PubMed: 30091969]

61. TEDS 2004-2014 National admissions to substance abuse treatment services. $2004 \mathrm{https}: / /$ www.samhsa.gov/data/sites/default/files/ 2014_Treatment_Episode_Data_Set_National_Admissions_9_19_16.pdf. Accessed August 26, 2018.

62. Ko JY, Wolicki S, Barfield WD, et al. CDC grand rounds: public health strategies to prevent neonatal abstinence syndrome. MMWR Morb Mortal Wkly Rep. 2017;66(9):242-245. 10.15585/ mmwr.mm6609a2. [PubMed: 28278146]

63. Patrick SW, Davis MM, Lehmann CU, Cooper WO, Cooper WO. Increasing incidence and geographic distribution of neonatal abstinence syndrome: United States 2009 to 2012. J Perinatol. 2015;35(8):650-655. 10.1038/jp.2015.36. [PubMed: 25927272]

64. Corr TE, Hollenbeak CS. The economic burden of neonatal abstinence syndrome in the United States. Addiction. 2017;112(9):1590-1599. 10.1111/add.13842. [PubMed: 28612362]

65. Broyles LM, Binswanger IA, Jenkins JA, et al. Confronting inadvertent stigma and pejorative language in addiction scholarship: a recognition and response. Subst Abus. 2014;35(3):217 10.1080/08897077.2014.930372. [PubMed: 24911031]

66. Olsen Y, Sharfstein JM. Confronting the stigma of opioid use disorder-and its treatment. JAMA. 2014;311(14):1393 10.1001/jama.2014.2147. [PubMed: 24577059]

67. Ashford RD, Brown AM, Curtis B. Substance use, recovery, and linguistics: the impact of word choice on explicit and implicit bias. Drug Alcohol Depend. 2018;189:131-138. 10.1016/ j.drugalcdep.2018.05.005. [PubMed: 29913324]

68. Kelly JF, Westerhoff CM. Does it matter how we refer to individuals with substance-related conditions? A randomized study of two commonly used terms. Int J Drug Policy. 2010;21(3):202207. 10.1016/j.drugpo.2009.10.010. [PubMed: 20005692]

69. Kelly JF, Saitz R, Wakeman S. Alcoholism Treatment Quarterly Language, Substance Use Disorders, and Policy: The Need to Reach Consensus on an \&quot;Addiction-ary\&quot; 2016. doi: 10.1080/07347324.2016.111310310.1080/07347324.2016.1113103doi.org/ 10.1080/07347324.2016.1113103doi.org/10.1080/07347324.2016.1113103 .

70. Everett A Final words. Psychiatr News. 2018;53(9). 10.1176/appi.pn.2018.5a24. appi.pn. $2018.5 \mathrm{a} 24$.

71. Friedmann PD, Schwartz RP. Just call it “treatment.”. Addict Sci Clin Pract. 2012;7(1):10 10.1186/1940-0640-7-10. [PubMed: 23186149]

72. Wakeman SE. Using science to battle stigma in addressing the opioid epidemic: opioid agonist therapy saves lives. Am J Med. 2016;129(5):455-456. 10.1016/j.amjmed.2015.12.028. [PubMed: 26836384]

73. Wakeman SE. Medications for addiction treatment. J Addict Med. 2017;11(1):1-2. 10.1097/ADM. 0000000000000275.

74. Mattick RP, Breen C, Kimber J, Davoli M. Buprenorphine maintenance versus placebo or methadone maintenance for opioid dependence. Cochrane Database Syst Rev. 2014(2):CD002207 10.1002/14651858.CD002207.pub4. [PubMed: 24500948]

75. U.S. Prescribing Rate Maps I Drug Overdose I CDC Injury Center. https://www.cdc.gov/ drugoverdose/maps/rxrate-maps.html. Accessed August 25, 2018.

76. Paulozzi LJ, Budnitz DS, Xi Y. Increasing deaths from opioid analgesics in the United States. Pharmacoepidemiol Drug Saf. 2006;15(9):618-627. 10.1002/pds.1276. [PubMed: 16862602] 
77. Paulozzi LJ. Opioid analgesic involvement in drug abuse deaths in American metropolitan areas. Am J Public Health. 2006;96(10):1755-1757. 10.2105/AJPH.2005.071647. [PubMed: 17008568]

78. Dunn KM, Saunders KW, Rutter CM, et al. Opioid prescriptions for chronic pain and overdose. Ann Intern Med. 2010;152(2):85 10.7326/0003-4819-152-2-201001190-00006. [PubMed: 20083827]

79. Gomes T, Mamdani MM, Dhalla IA, Paterson JM, Juurlink DN. Opioid dose and drug-related mortality in patients with non-malignant pain. Arch Intern Med. 2011;171(7). 10.1001/ archinternmed.2011.117.

80. Miller M, Barber CW, Leatherman S, et al. Prescription opioid duration of action and the risk of unintentional overdose among patients receiving opioid therapy. JAMA Intern Med. 2015;175(4): 608 10.1001/jamainternmed.2014.8071. [PubMed: 25686208]

81. Bohnert ASB. Association Between Opioid Prescribing Patterns and Opioid Overdose-Related Deaths. JAMA. 2011;305(13):1315 10.1001/jama.2011.370. [PubMed: 21467284]

82. Park TW, Saitz R, Ganoczy D, Ilgen MA, Bohnert ASB. Benzodiazepine prescribing patterns and deaths from drug overdose among US veterans receiving opioid analgesics: case-cohort study. BMJ. 2015;350:h2698 http://www.ncbi.nlm.nih.gov/pubmed/26063215 Accessed July 22, 2018. [PubMed: 26063215]

83. Glanz JM, Narwaney KJ, Mueller SR, et al. Prediction model for two-year risk of opioid overdose among patients prescribed chronic opioid therapy. J Gen Intern Med. 12018 10.1007/ s11606-017-4288-3.

84. Dowell D, Haegerich TM, Chou R. CDC guideline for prescribing opioids for chronic Pain United States, 2016. MMWR Recomm Reports. 2016;65(1):1-49. 10.15585/mmwr.rr6501e1er.

85. Feldman L, Skeel Williams K, Knox M, Coates J. Influencing controlled substance prescribing: attending and resident physician use of a state prescription monitoring program. Pain Med. 2012;13(7):908-914. 10.1111/j.1526-4637.2012.01412.x. [PubMed: 22681237]

86. Early Assessment of the Prescription Drug Monitoring Program: A Survey of Providers. 2013 http://www.orpdmp.com/orpdmpfiles/PDF_Files/Reports/PDES_PDMPeval_01.10.13.pdf; Accessed August 26, 2018.

87. Prescription Drug Monitoring Program Center of Excellence at Brandeis Briefing on PDMP Effectiveness. www.pdmpex-cellence.org. Accessed August 26, 2018.

88. Patrick SW, Fry CE, Jones TF, Buntin MB. Implementation of prescription drug monitoring programs associated with reductions in opioid-related death rates. Health Aff. 2016;35(7):13241332. 10.1377/hlthaff.2015.1496.

89. Fareed A, Vayalapalli S, Casarella J, Amar R, Drexler K. Heroin anticraving medications: a systematic review. Am J Drug Alcohol Abuse. 2010;36(6):332-341. 10.3109/00952990.2010.505991. [PubMed: 20955107]

90. Schuckit MA. Treatment of opioid-use disorders Longo DL, ed. N Engl J Med. 2016;375(4):357368. 10.1056/NEJMra1604339. [PubMed: 27464203]

91. Minozzi S, Amato L, Vecchi S, Davoli M, Kirchmayer U, Verster A. Oral naltrexone maintenance treatment for opioid dependence In: Minozzi S, ed, Cochrane Database of Systematic Reviews, Chichester, UK: John Wiley \& Sons, Ltd; 2011:CD001333 10.1002/14651858.CD001333.pub4.

92. Krupitsky E, Nunes E V, Ling W, Illeperuma A, Gastfriend DR, Silverman BL. Injectable extended-release naltrexone for opioid dependence: a double-blind, placebo-controlled, multicentre randomised trial. Lancet (London, England). 2011;377(9776):1506-1513. 10.1016/ S0140-6736(11)60358-9.

93. Krupitsky E, Zvartau E, Blokhina E, et al. Randomized trial of long-acting sustained-release naltrexone implant vs oral naltrexone or placebo for preventing relapse to opioid dependence. Arch Gen Psychiatry. 2012;69(9):973 10.1001/archgenpsychiatry.2012.1a. [PubMed: 22945623]

94. Saucier R, Wolfe D, Dasgupta N. Review of case narratives from fatal overdoses associated with injectable naltrexone for opioid dependence. Drug Saf. 32018 10.1007/s40264-018-0653-3.

95. Binswanger IA, Glanz JM. Potential risk window for opioid overdose related to treatment with extended-release injectable naltrexone. Drug Saf. 2018(8). 10.1007/s40264-018-0705-8. 
96. Thomas CP, Fullerton CA, Kim M, et al. Medication-assisted treatment with buprenorphine: assessing the evidence. Psychiatr Serv. 2014;65(2):158-170. 10.1176/appi.ps.201300256. [PubMed: 24247147]

97. Fullerton CA, Kim M, Thomas CP, et al. Medication-assisted treatment with methadone: assessing the evidence. Psychiatr Serv. 2014;65(2):146-157. 10.1176/appi.ps.201300235. [PubMed: 24248468]

98. Nielsen S, Larance B, Degenhardt L, Gowing L, Kehler C, Lintzeris N. Opioid agonist treatment for pharmaceutical opioid dependent people. Cochrane Database Syst Rev. 2016(5): CD011117 10.1002/14651858.CD011117.pub2. [PubMed: 27157143]

99. Mattick RP, Breen C, Kimber J, Davoli M. Methadone maintenance therapy versus no opioid replacement therapy for opioid dependence. Cochrane Database Syst Rev. 2009(3):CD002209 10.1002/14651858.CD002209.pub2. [PubMed: 19588333]

100. Mathers BM, Degenhardt L, Bucello C, Lemon J, Wiessing L, Hickman M. Mortality among people who inject drugs: a systematic review and meta-analysis. Bull World Health Organ. 2013;91(2):102-123. 10.2471/BLT.12.108282. [PubMed: 23554523]

101. Degenhardt L, Randall D, Hall W, Law M, Butler T, Burns L. Mortality among clients of a statewide opioid pharmacotherapy program over 20 years: risk factors and lives saved. Drug Alcohol Depend. 2009;105(1-2):9-15. 10.1016/j.drugalcdep.2009.05.021. [PubMed: 19608355]

102. Sordo L, Barrio G, Bravo MJ, et al. Mortality risk during and after opioid substitution treatment: systematic review and meta-analysis of cohort studies. BMJ. 2017;357:j1550 http:// www.ncbi.nlm.nih.gov/pubmed/28446428 Accessed August 21, 2018. [PubMed: 28446428]

103. DEA Requirements for DATA Waived Physicians (DWPs). https://www.deadiversion.usdoj.gov/ pubs/docs/dwp_buprenorphine.htm. Accessed August 22, 2018.

104. Jones CM, Campopiano M, Baldwin G, McCance-Katz E. National and state treatment need and capacity for opioid agonist medication-assisted treatment. Am J Public Health. 2015;105(8):e55 e63. 10.2105/AJPH.2015.302664.

105. Andrilla CHA, Moore TE, Patterson DG, Larson EH. Geographic Distribution of providers with a DEA waiver to prescribe buprenorphine for the treatment of opioid use disorder: a 5-year update. J Rural Heal. 2018(6). 10.1111/jrh.12307.

106. Substance Use During Pregnancy I Guttmacher Institute. https://www.guttmacher.org/state-policy/ explore/substance-use-during-pregnancy. Accessed July 22, 2018.

107. Clinical Guidance for Treating Pregnant and Parenting Women with Opioid Use Disorder and Their Infants ii Clinical Guidance for Treating Pregnant and Parenting Women With Opioid Use Disorder and Their Infants. http://store.samhsa.gov. Accessed July 6, 2018.

108. Jones HE, Martin PR, Heil SH, et al. Treatment of opioid-dependent pregnant women: Clinical and research issues. J Subst Abuse Treat. 2008;35(3):245-259. 10.1016/j.jsat.2007.10.007. [PubMed: 18248941]

109. Jones HE, Terplan M, Meyer M. Medically assisted withdrawal (Detoxification). J Addict Med. 2017;11(2):90-92. 10.1097/ADM.0000000000000289. [PubMed: 28079573]

110. Kim D, Irwin KS, Khoshnood K. Expanded access to naloxone: options for critical response to the epidemic of opioid overdose mortality. Am J Public Health. 2009;99(3):402-407. 10.2105/ AJPH.2008.136937. [PubMed: 19150908]

111. Mueller SR, Walley AY, Calcaterra SL, Glanz JM, Binswanger IA. A review of opioid overdose prevention and naloxone prescribing: implications for translating community programming into clinical practice. Subst Abus. 2015;36(2):240-253. 10.1080/08897077.2015.1010032. [PubMed: 25774771]

112. Walley AY, Xuan Z, Hackman HH, et al. Opioid overdose rates and implementation of overdose education and nasal naloxone distribution in Massachusetts: interrupted time series analysis. BMJ. 2013;346:f174 10.1136/BMJ.F174. [PubMed: 23372174]

113. Clark AK, Wilder CM, Winstanley EL. A systematic review of community opioid overdose prevention and naloxone distribution programs. J Addict Med. 2014;8(3):153-163. 10.1097/ ADM.0000000000000034. [PubMed: 24874759] 
114. Doyon S, Benton C, Anderson BA, et al. Incorporation of poison center services in a state-wide overdose education and naloxone distribution program. Am J Addict. 2016;25(4):301-306. 10.1111/ajad.12384. [PubMed: 27219823]

115. Doe-Simkins M, Quinn E, Xuan Z, et al. Overdose rescues by trained and untrained participants and change in opioid use among substance-using participants in overdose education and naloxone distribution programs: a retrospective cohort study. BMC Public Health. 2014;14(1):297 10.1186/1471-2458-14-297. [PubMed: 24684801]

116. Wagner KD, Valente TW, Casanova M, et al. Evaluation of an overdose prevention and response training programme for injection drug users in the Skid Row area of Los Angeles, CA. Int J Drug Policy. 2010;21(3):186-193. 10.1016/j.drugpo.2009.01.003. [PubMed: 19268564]

117. HHS, Samhsa, Capt. Samhsa's Center for the Application of Prevention Technologies Preventing the Consequences of Opioid Overdose: Understanding Naloxone Access Laws. https:// www.samhsa.gov/capt/. Accessed July 22, 2018. 


\section{Table 1}

DSM V diagnostic criteria for opioid use disorder. ${ }^{36}$

Two or more of the following within a 12-month period:

- Using larger amounts of opioids or over a longer period of time than was intended

- Persistent desire to cutback or unsuccessful efforts to control use

- Substantial amount of time spent obtaining, using or recovering from use

- Craving or strong desire to use opioids

- Failure to fulfill obligations at work, home or school due to use

- Continued use despite recurrent social or interpersonal problems caused or exacerbated by use

- Giving up or reducing social, occupational or recreational activities due to use

- Recurrent opioid use in situations that may be physically dangerous

- Continued use despite knowledge of having a physical or psychological problem caused or exacerbated by opioids

- Tolerance *

- Development of withdrawal syndrome if use stopped *

Opioid use disorder severity:

- Mild 2-3 symptoms or signs

- Moderate 4-5 symptoms or signs

- Severe 6 or more symptoms or signs

Tolerance and withdrawal criteria not met if opioids only used under medical supervision and as intended. 


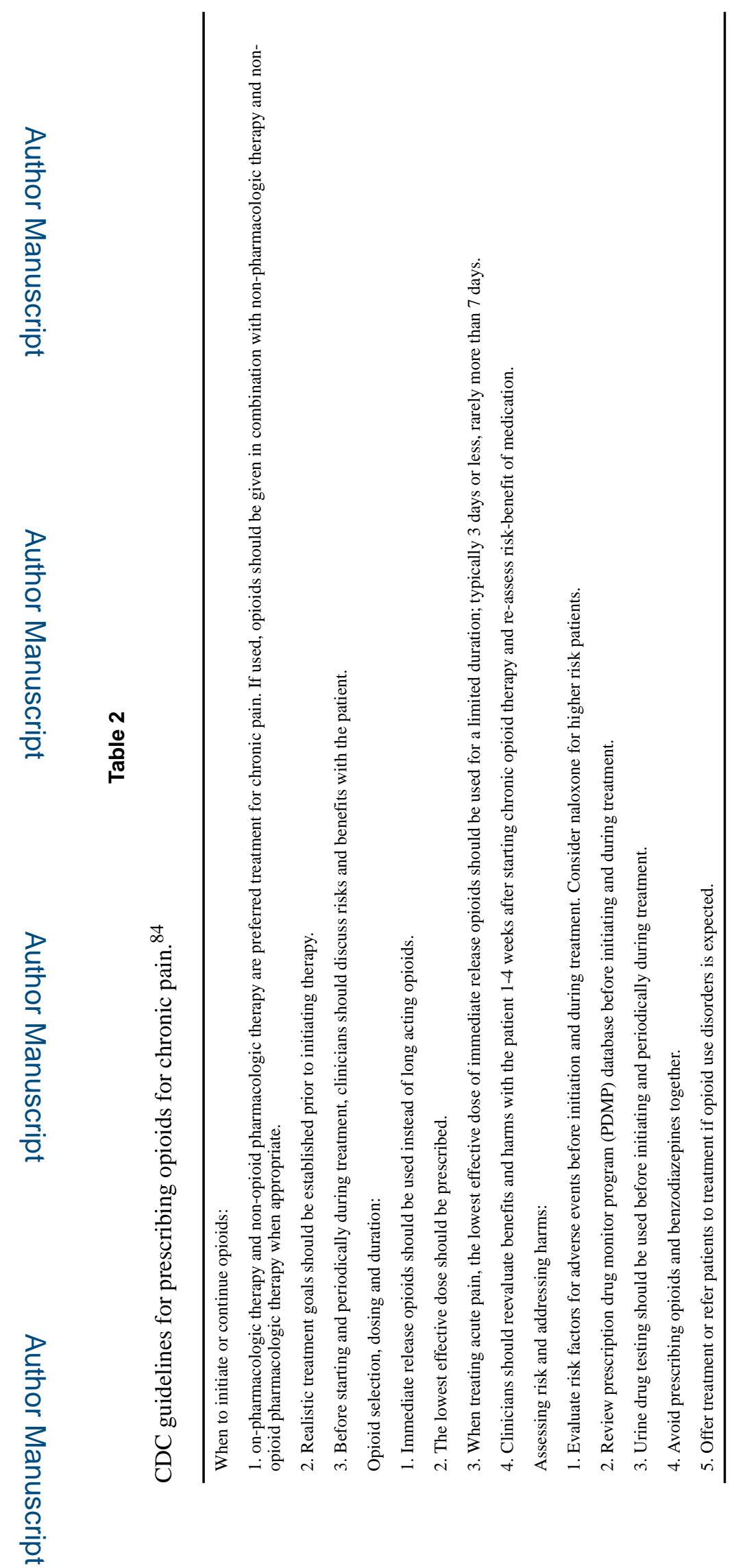

Semin Perinatol. Author manuscript; available in PMC 2020 April 01. 